\title{
A Mathematical Technique for Analyzing Folds With the Computer Program "FOLDPI"
}

\author{
Nabeel K. Al-Azzawi \\ Department of Geology \\ College of Science \\ Mosul University
}

(Received 30/4/2006, Accepted 20/9/2006)

\begin{abstract}
A mathematical technique for analyzing folds was proposed instead of the tedious and slow graphical method. Procedure of this technique comprises converting the data of bedding planes to pole attitudes, calculation of the mean pole vector of fold limbs, obtaining the best fit $\pi$-circle, determining the fold geometric properties and finding fold cylindricity. This procedure was carried out by FOLDPI, a GWBASIC computer program written for the purpose of this application. Most of the geometrical properties of fold were dealt with. In addition, an example taken from the Sinjar Anticline was used for testing the validity of this technique. The results of testing the program against manually obtained solutions proved that this technique can be very helpful in getting faster and more accurate results
\end{abstract}

\section{ط طرقة رباضية التحلل الليلت بلستخدلم البرنامج الحسوي FOLDPI}

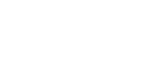

"قُقترحت هذه الطريقة الرياضية لتحليل الطيلت بدلاً من الطريقة البيانية للساقة (طريقةشكل باي). تتضمن هذه الطريقة تحويل قراءات وضعيلت مستويت الطقات إلى وضعيلت الأفطلب ثم إيجاد الاتج له الجيبتملمي لهذه المتجهات (الأظطلب)، مسلب معل وضعية جن الحي الطي ة والمطق ـة المفص لية (إن وجدت)، ليجاد أفضل دائرة باي تَمله بمعل وضعية جنلهي الطية، مسلب الص فلت الهنهس ية الطي ـة ولخيرأ إيجاد درجة للطوانية الطية. وألدق بهذه الطريقة البرنلمج الحلسوبي FOLDPI وهو برنلمج "أعد

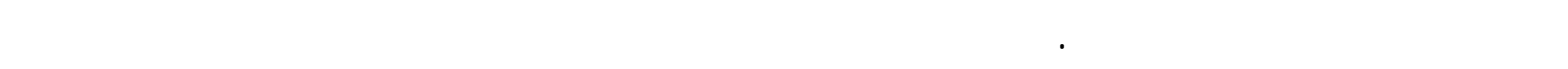

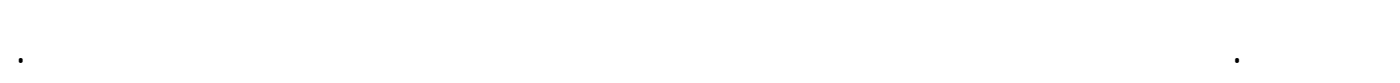

\section{INTRODUCTION}

Conventionally, folds were analyzed using the common graphical technique of $\pi$ diagram, which is one of the stereographic projection applications. This graphical method has a worldwide usage and it has an advantage of graphically showing fold geometry but it is tedious and time consuming specially in plotting and counting the S-poles on the 
stereonet. Recently, and for the sake of faster and easier techniques, many structural geologists have attempted to modify their related methods towards the trend of mathematics and computer programming approaches. Accordingly, the present author suggests a mathematical technique for digital execution of this $\pi$-diagram and the determinion of the geometric parameters of folds using mathematics and computer program.

Previously, some authors made contributions in this trend. They performed some steps in this respect. Ramsay (1967) suggested two mathematical techniques in the scope of fold analysis. The first was applied for determination of unimodal poles distribution by vectors of directional cosines. While the second method was used for determining the best-fit $\pi$-circles of cylindrical folds. Bengston (1980) mentioned, marginally, about this idea through out his study of tangent diagram. Ramsay and Huber (1987) described the methods of Ramsay (1967) by " the accuracy contained in such methods is only justified if it is imperative to exploit the full potential of very precise primary data".

$\pi$-diagram of fold analysis is a method applied by using an equal area stereographic projection (stereonet) to plot the perpendiculars to the bedding planes (S-poles). Attitudes of such bedding planes are collected along traverse which must be transverse to the fold axis. Plotting the S-poles of such a fold (point diagram), counting the concentration of points in $1 \%$ of the stereonet area, and lastly contouring the counted values in the form of contour percentages (contour \%) to produce the $\pi$-diagram of this fold. The advantage of this diagram is the geometric view of the fold parameters. Such parameters are fold axis, fold plunge, fold symmetry, interlimb angle and attitude of axial plane.

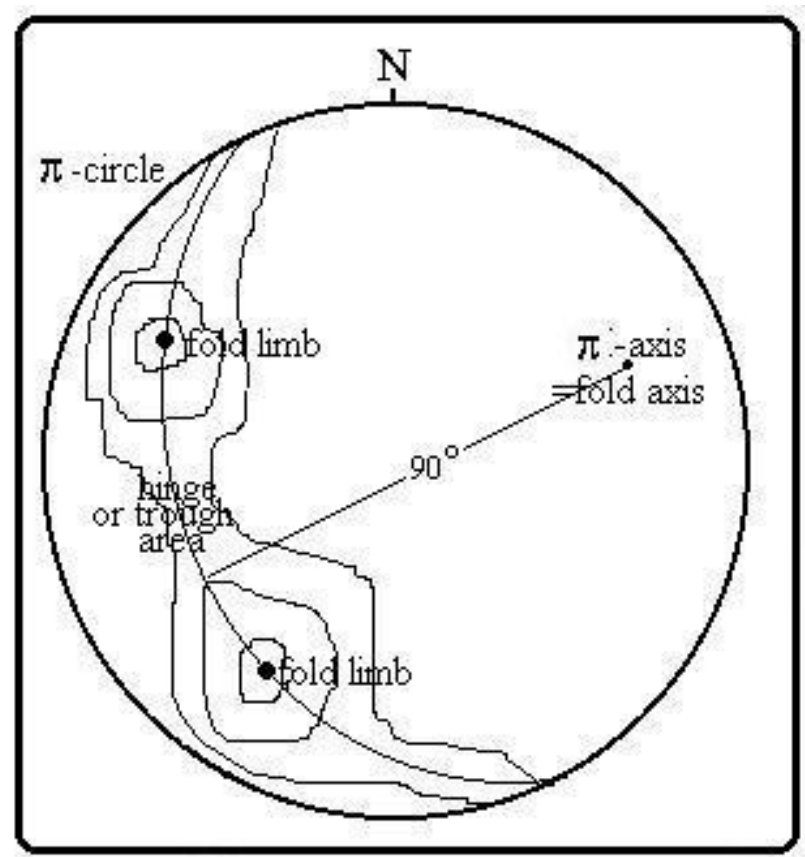

Fig.(1) Schematic $\pi$-diagram contents of any fold

In $\pi$-diagram, if the fold is perfectly cylindrical, the bedding S-poles fall, perfectly, along a great circle of the stereonet ( $\pi$-circle). When the fold transforms geometrically to non-cylindrical types, the scattering of the poles around $\pi$-circle becomes more pronounced. The perpendicular to the $\pi$-circle is called $\pi$-axis that is coinciding with the 
fold axis. Consequently, if the fold is perfectly cylindrical the angle between each S-pole and fold axis is perfectly $90^{\circ}$ (Fig. 1). Practically, the S-poles of any natural fold do not lie exactly on a certain great circle but fall in zone around this circle. Nevertheless, the human error in field measurements plays a role in the accuracy of these measurements; which amount to \pm 2 degree (Ramsay and Huber, 1987). However, the mean reason responsible for the scattering of S-poles is the absence of perfectly cylindrical folds in the field. Many of natural folds are of cylindrical, sub-cylindrical and non-cylindrical styles. In this respect Ramsay (1967) designed his method for determining the best-fit $\pi$-circles for perfectly cylindrical folds. This is because only in this type of folds the $\pi$-axis makes a right angle with each S-pole; and he built up his mathematics on this property. It must be mentioned that in Ramsay (1967) terminology, the term cylindrical fold is analogous to perfectly cylindrical one. In the more recent synthesis, Ramsay and Huber (1987) classified the folds into perfectly cylindrical, cylindrical, sub-cylindrical and noncylindrical types (Fig. 2). Previously, folds classified as cylindrical and non-cylindrical and some time cylindroid (Fleuty, 1964). In the classification of Ramsay and Huber(1987) the perfectly cylindrical fold has its S-poles lie perfectly on the $\pi$-circle.

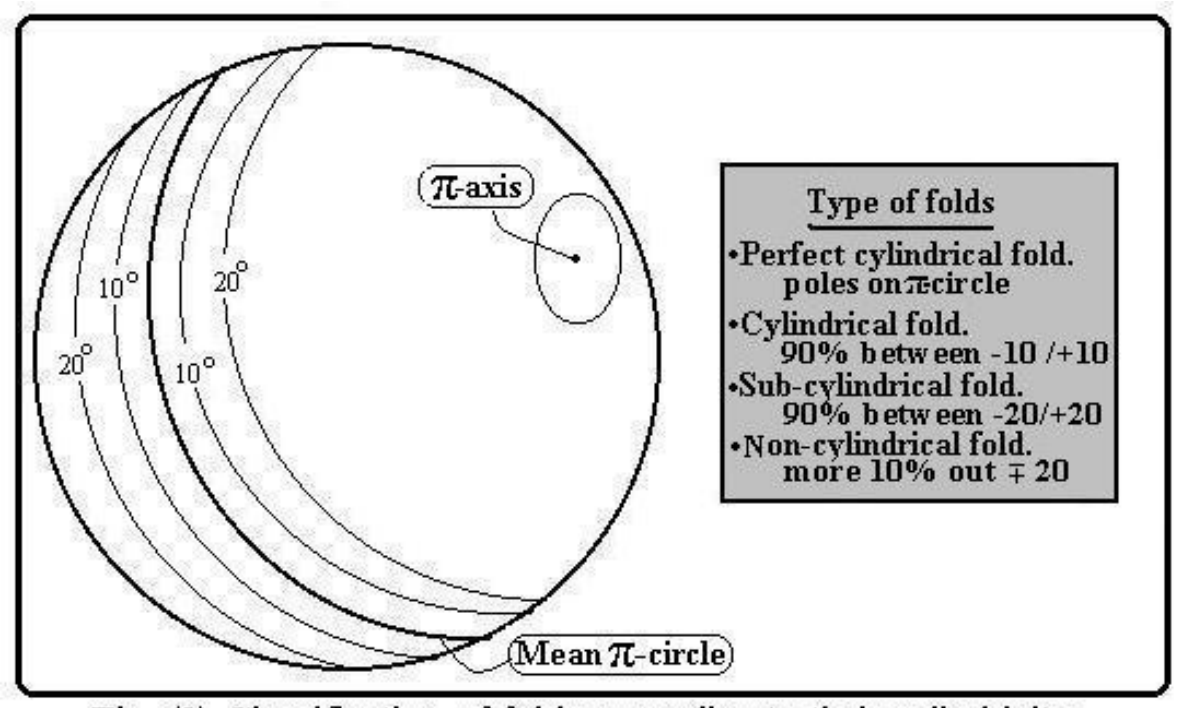

Fig. (2).Classification of folds according to their cylindricity (after Ramsay and Huber, 1987)

While if more than $90 \%$ of the S-poles fall within an angle of $\pm 10^{\circ}$ from the constructed $\pi$-circle the fold should be termed cylindrical. But if more than $90 \%$ of the data lie within $\pm 20^{\circ}$ of the $\pi$-circle the fold is then called sub-cylindrical fold. Folds with more than $10 \%$ of their S-poles falling outside the limit of $\pm 20^{\circ}$ are termed noncylindrical (Fig. 2). In addition to the scope of the present work, the author extended the method of Ramsay (1967) from its application only on perfectly cylindrical to include all types of folds described by Ramsay and Huber (1987). This extension was based on the styles of poles distribution a round the best-fit $\pi$-circle. 


\section{METHODOLOGY}

The proposed mathematical method comprises the following procedures:

1st- Converting the data of bedding plane attitudes of both fold limbs (strike direction/dip amount when strike was taken clockwise from dip direction) to pole attitude (dip direction/dip amount) and finally to their corresponding directional cosine vectors $(\alpha, \beta \& \gamma)$.

2nd- Calculation of the mean vector of each fold limb and hinge area by unimodal poles distribution method (summing method).

3rd- Obtaining the best-fit $\pi$-circle for these two means of fold limbs, or three means (two limbs and a hinge area)

4th- Determination of fold parameters which reflect its geometry.

5th- Determination of the cylindricity of folds according to Ramsay and Huber (1987).

\section{1st- Determination of directional cosines :}

Mathematical equations needed for the determination of directional cosines from attitudes of bedding planes are derived in this work. So the angles $\boldsymbol{\alpha}, \boldsymbol{\beta} \boldsymbol{\&} \boldsymbol{\gamma}$ are determined from strike directions and dip amounts. The following steps explain this procedure.

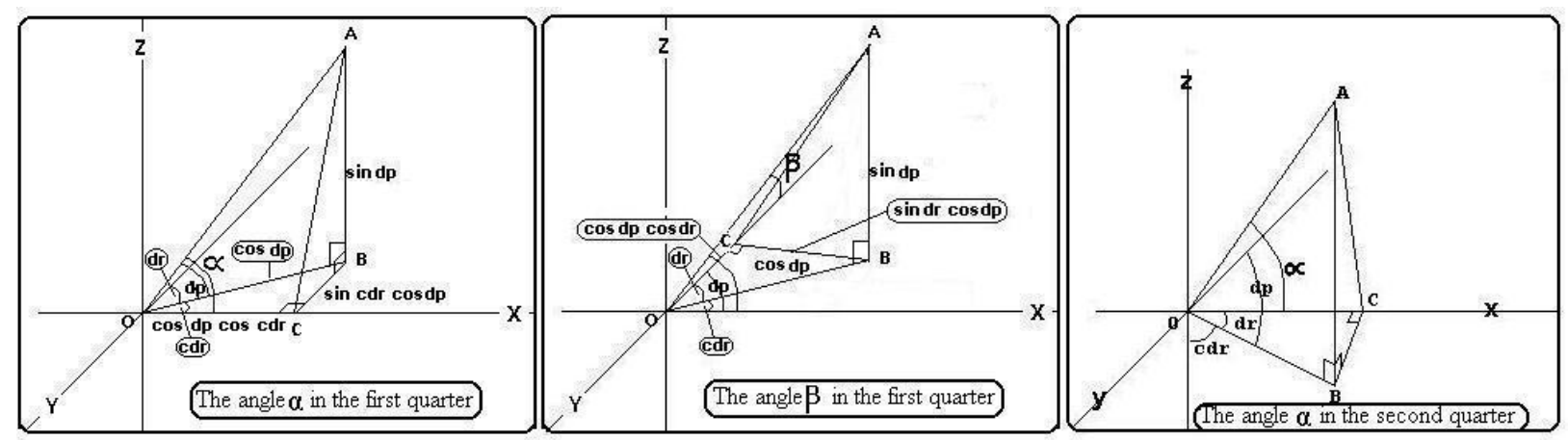

Fig. ( 3 ). Determination of the angles $\alpha$ and $\beta$ from strike direction and dip amount of the bedding plane.

1. Conversion of bedding plane attitudes (strike direction /dip amount) to pole attitude (dip direction / dip amount).

So, $d r=90+d s \quad, \quad d p=90-d p l \quad c d r=90-d r$

Where $d r$ and $d p$ are the angles of dip direction and dip amount of the pole, $d s$ and $d p l$ are of strike direction and dip amount of the bedding plane and $c d r$ is the complimentary angle of $d r$.

2. Determination of the directional cosines. These can fall into four cases. Each case represents one of the upper four quarters of the Cartesian coordinate. It must be mentioned that in the four cases the angle $\gamma$ is always equal to $(90-d p)$ with negative sign (Fig.4).

The first case: if the pole of any plane falls in the first quarter (Fig.3).

Determination of the angle $\alpha$ :

In Figure (3), suppose the line $O A$ in the triangle $O A B$ is unity. Then

$A B=\sin d p$ and $O B=\cos d p$. 
In the triangle $\mathrm{OBC}$ the angle $\mathrm{OCB}$ is a right angle, then

Also

Sin $c d r=C B / O B \quad$ so $\quad C B=\operatorname{Cos} d p$. Sin $c d r$

$\operatorname{Cos} c d r=O C / O B$ so $O C=\operatorname{Cos} c d r . \operatorname{Cos} d p$

According to Pythagorean Theorem

$(A C) 2=(A B) 2+(B C) 2$

Therefore,

$(A C) 2=\operatorname{Sin} 2 d p+\operatorname{Cos} 2 d p \cdot \operatorname{Sin} 2 c d r$

And, in the triangle $\mathrm{OAC}$

$$
\begin{aligned}
& (A C) 2=(O C) 2+(O A) 2-2 . O C . O A . \operatorname{Cos} \alpha \\
& \operatorname{Cos} \alpha=[(O C) 2+(O A) 2-(A C) 2] /(2 . O C . O A)
\end{aligned}
$$

Resultant, the equation which is shown below is used for the determination of $\operatorname{Cos} \alpha$ :

$\operatorname{Cos} \alpha=\left[\operatorname{Cos}^{2} c d r \cdot \operatorname{Cos}^{2} d p+1-\operatorname{Sin}^{2} d p-\operatorname{Cos}^{2} d p \cdot \operatorname{Sin}^{2} c d r\right] /[2 . \operatorname{Cos} c d r \cdot \operatorname{Cos} d p]$

\section{Determination of the angle $\beta$ :}

In the triangle $O A B, O B A$ is a right angle, suppose the hypotenuse $O A$ is unity (Fig.

3). Therefore,

$O B=\operatorname{Cos} d p \quad$ and $\quad A B=\operatorname{Sin} d p$

The angle $B C O$ in the triangle $B C O$ was drawn to be $90^{\circ}$. So,

Sin $d r=C B / \operatorname{Cos} d p \quad$ so $\quad C B=\operatorname{Sin} d r$. Cos $d p$

$\operatorname{Cos} d r=O C / \operatorname{Cos} d p \quad$ so $\quad O C=\operatorname{Cos} d r . \operatorname{Cos} d p$

$A B C$ is a right triangle, So according to the Pythagorean theorem

Then,

$$
(A C) 2=(C B) 2+(A B) 2
$$

$(A C) 2=\operatorname{Sin} 2 d r \cdot \operatorname{Cos} 2 d p+\operatorname{Sin} 2 d p$

Lastly, in the triangle $A O C$

$$
\begin{aligned}
& (A C) 2=(O A) 2+(O C) 2-2 \cdot O A \cdot O C \cdot \operatorname{Cos} \beta \\
& \operatorname{Cos} \beta=(1+(O C) 2-(A C) 2) /(2 . O C)
\end{aligned}
$$

Resultant, the equation listed below, determine $\operatorname{Cos} \beta$ :

$\operatorname{Cos} \beta=\left[\operatorname{Cos}^{2} d r \cdot \operatorname{Cos}^{2} d p+1-\operatorname{Sin}^{2} d p-\operatorname{Cos}^{2} d p \cdot \operatorname{Sin}^{2} d r\right] /[2 . \operatorname{Cos} d r \cdot \operatorname{Cos} d p]$

It must be noted that this equation is similar to that equation of $\operatorname{Cos} \alpha$, accept the angle $c d r$ is replaced by the angle $d r$. In this case, when the angle $\alpha$ fall in the first quarter it has a positive sign whereas the angle $\beta$ is negative (Fig. 4). 


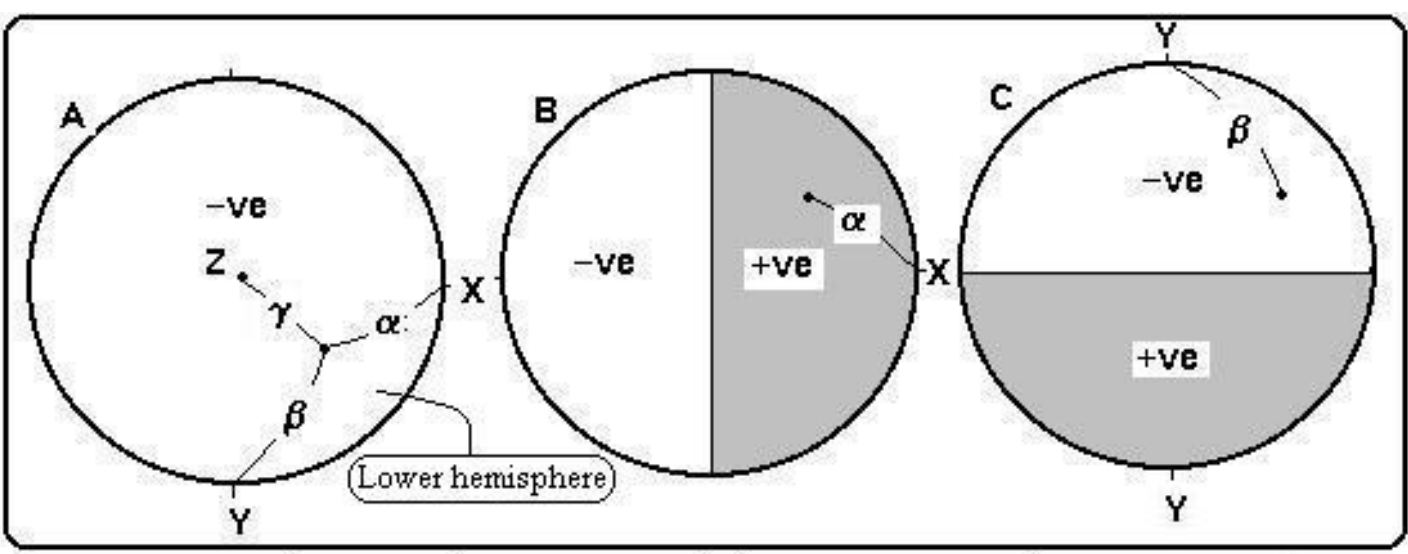

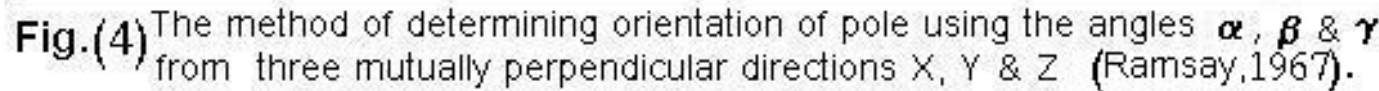

The second case: If the pole of any plane falls in the second quarter (Fig. 3). Therefore, drnew $=$ drold -90 $c d r=90-d r$

Similar to the first case, the angle $\alpha$ and $\beta$ can be determined by:

$$
\operatorname{Cos} \alpha=\left[\operatorname{Cos}^{2} d r \cdot \operatorname{Cos}^{2} d p+1-\operatorname{Sin}^{2} d p-\operatorname{Cos}^{2} d p \cdot \operatorname{Sin}^{2} d r\right] /[2 . \operatorname{Cos} d r \cdot \operatorname{Cos} d p]
$$

And,

$\operatorname{Cos} \beta=\left[\operatorname{Cos}^{2} c d r \cdot \operatorname{Cos}^{2} d p+1-\operatorname{Sin}^{2} d p-\operatorname{Cos}^{2} d p \cdot \operatorname{Sin}^{2} c d r\right] /[2 \cdot \operatorname{Cos} c d r \cdot \operatorname{Cos} d p]$

In this case, both $\alpha$ and $\beta$ have positive signs (Fig. 4).

The third case: If the pole of any plane falls into the third quarter.

Then,

$$
\text { drnew }=\text { drold }-180
$$

Similarly,

$$
c d r=90-d r
$$

$$
\operatorname{Cos} \alpha=\left[\operatorname{Cos}^{2} c d r \cdot \operatorname{Cos}^{2} d p+1-\operatorname{Sin}^{2} d p-\operatorname{Cos}^{2} d p \cdot \operatorname{Sin}^{2} c d r\right] /[2 \cdot \operatorname{Cos} c d r \cdot \operatorname{Cos} d p]
$$

And

$$
\operatorname{Cos} \beta=\left[\operatorname{Cos}^{2} d r \cdot \operatorname{Cos}^{2} d p+1-\operatorname{Sin}^{2} d p-\operatorname{Cos}^{2} d p . \operatorname{Sin}^{2} d r\right] /[2 . \operatorname{Cos} d r . \operatorname{Cos} d p]
$$

In this quarter, $\alpha$ has negative sign. While $\beta$ is positive (Fig. 4).

The forth case: When the pole lies in the forth quarter.

Therefore,

$$
\begin{aligned}
& d r n e w=d r \text { old }-270 \\
& c d r=90-d r
\end{aligned}
$$

Similar to the previous cases, the angles $\alpha$ and $\beta$ can be determined by the following equations:

$$
\operatorname{Cos} \alpha=\left[\operatorname{Cos}^{2} d r \cdot \operatorname{Cos}^{2} d p+1-\operatorname{Sin}^{2} d p-\operatorname{Cos}^{2} d p \cdot \operatorname{Sin}^{2} d r\right] /[2 \cdot \operatorname{Cos} d r . \operatorname{Cos} d p]
$$

And 
$\operatorname{Cos} \beta=\left[\operatorname{Cos}^{2} c d r \cdot \operatorname{Cos}^{2} d p+1-\operatorname{Sin}^{2} d p-\operatorname{Cos}^{2} d p \cdot \operatorname{Sin}^{2} c d r\right] /[2 \cdot \operatorname{Cos} c d r \cdot \operatorname{Cos} d p]$

In this quarter, the angles $\alpha$ and $\beta$ have negative signs. Resultant, data of poles (directions and dip amounts) representing bedding planes are converted to directional cosines which represented by the cosines of the angles $\alpha, \beta$ and $\gamma$.

\section{2nd- The unimodal pole distribution method:}

The unimodal pole distribution was suggested and described by Ramsay (1967). It is also called method of summing vectors. Considering the pole as a unit vector, the method is used for determining the mean vector of poles of any geologic planes. This is done after determining the angles $\alpha, \beta$ and $\gamma$ of each pole (unit vector) with respect to the coordinate axes $\mathrm{x}, \mathrm{y}$ and $\mathrm{z}$ respectively (Fig. 5A). These angles, in the present work, are an output of the previous procedure (mentioned in $1 \mathrm{st}$ ). The $\mathrm{x}, \mathrm{y}$, and $\mathrm{z}$ components of the side of the vector box (Fig. 5B) for each measurement are then calculated by $\operatorname{Cos} \alpha, \operatorname{Cos} \beta$ and $\operatorname{Cos} \gamma$ respectively. These directional cosines are determined for all poles and sums of the vector components are calculated $(\Sigma \cos \alpha, \Sigma \cos \beta$ and $\Sigma \cos \gamma)$. These sums give the dimentions of the $x, y$, and $z$ components of the total vector sum and the diagonal of this box gives the strength of the total vector sum (TVS) which is equal to:

$$
T V S=[(\Sigma \cos \alpha) 2+(\Sigma \cos \beta) 2+(\Sigma \cos \gamma) 2] 1 / 2-----(\text { Ramsay, 1967) }
$$

Therefore, the mean vector direction with respect to $\mathrm{x}, \mathrm{y}$ and $\mathrm{z}$ axes are given by:

$\operatorname{Cos} \alpha^{-}=\Sigma \cos \alpha /$ TVS ------------- 1

$\operatorname{Cos} \beta^{-}=\Sigma \cos \beta / T V S$

$\operatorname{Cos} \gamma^{-}=\Sigma \cos \gamma /$ TVS

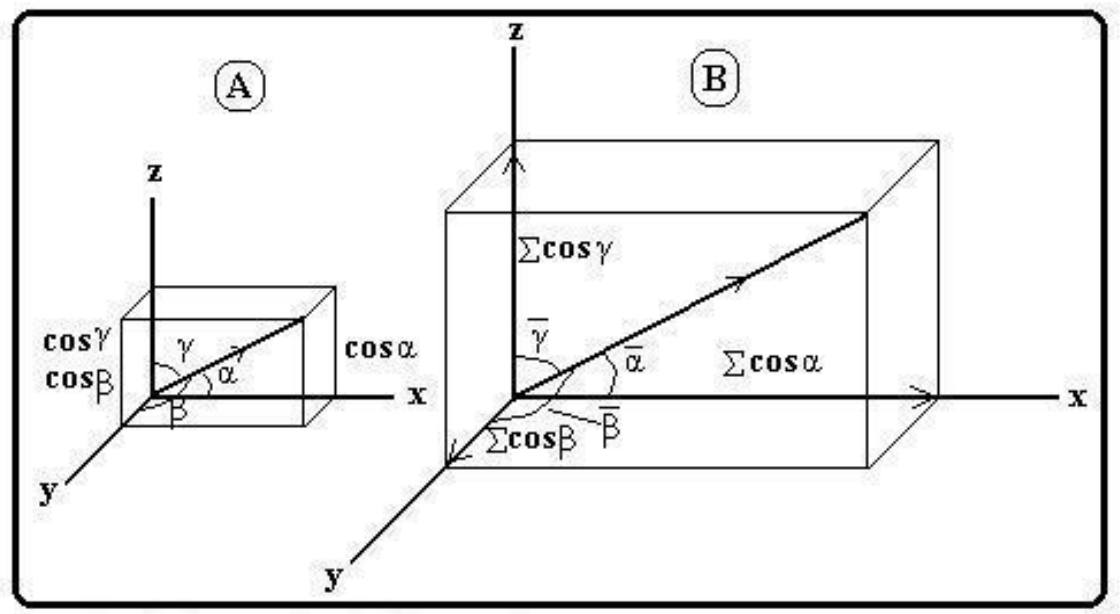

Fig. ( 5 ) Method of summing vectors(After Ramsay,1967)•

In the course of this work, data that were taken from a fold can be differentiated into two or three concentrations. If the folds are of chevronic or mostly chevronic style, two concentrations of pole distribution are found. That is because the hinge is angular and there is no hinge area then the two concentrations representing the two limbs. Whereas, in the box type folds or near this shape, three concentrations are found. Two of them for the limbs and the third represent the hinge area. It means that each fold has two or three mean vectors. Consequently, the users of this method (Unimodal poles distribution) must process each concentration of fold poles and determine the mean vector of each one. These mean vectors (with the angles $\alpha, \beta$ and $\gamma$ ) can be used for determining the best-fit 
$\pi$-circle of such a fold. Mean vectors can be plotted manually by setting the angles $\alpha, \beta$ and $\gamma$ on the stereonet or they can be processed mathematically to determine the fold $\pi$ circle.

\section{3rd- Determination of best fit $\pi$-circle of folds:}

Fold $\pi$-circle, as it mentioned above, is a stereographic best-fitted great circle to bedding S-poles. The method for determining the best-fit $\pi$-circles was suggested by Ramsay (1967). In this method, $\pi$-axis was determined mathematically by finding the normal to each bedding S-poles of perfectly cylindrical fold. Then $\pi$-circle can be drown, stereographiclly, perpendicular to this normal. The method was based on the usual technique of minimizing the squares of the deviations of the observed bedding S-poles from this surface.

Ramasy (1967; pp.18-20) designed this method for number of poles that fall perfectly on the $\pi$-circle, so this method is constrained for perfectly cylindrical folds only.

The present author made a simple modification for wider range of applications including cylindrical and sub-cylindrical fold, which are dominant in the field. Therefore, it is modified by obtaining the mean vector of large number of poles for the two fold limbs or two-fold limbs and hinge area by the unimodal pole distribution. Then, determining of the $\pi$-circle best fitted to the two or the three concentrations. By this way of drawing the $\pi$-cirle, limits of $\pm 10^{\circ}$ and $\pm 20^{\circ}$ from $\pi$-cirle can be plotted and type of fold cylindricity can be found (As in E). According to this modification many types of folds can be identified.

The method was described in (Ramsay, 1967), and it is summarized here as the following:

Suppose $\alpha, \beta$ and $\gamma$ are angles between $\pi$-axis vector of any fold and the three coordinate axes $X, Y$ and $Z$ respectively. Also, suppose $a, b$ and $c$ are angles between any bedding S-pole vector and the same coordinate axes (Fig. 6).

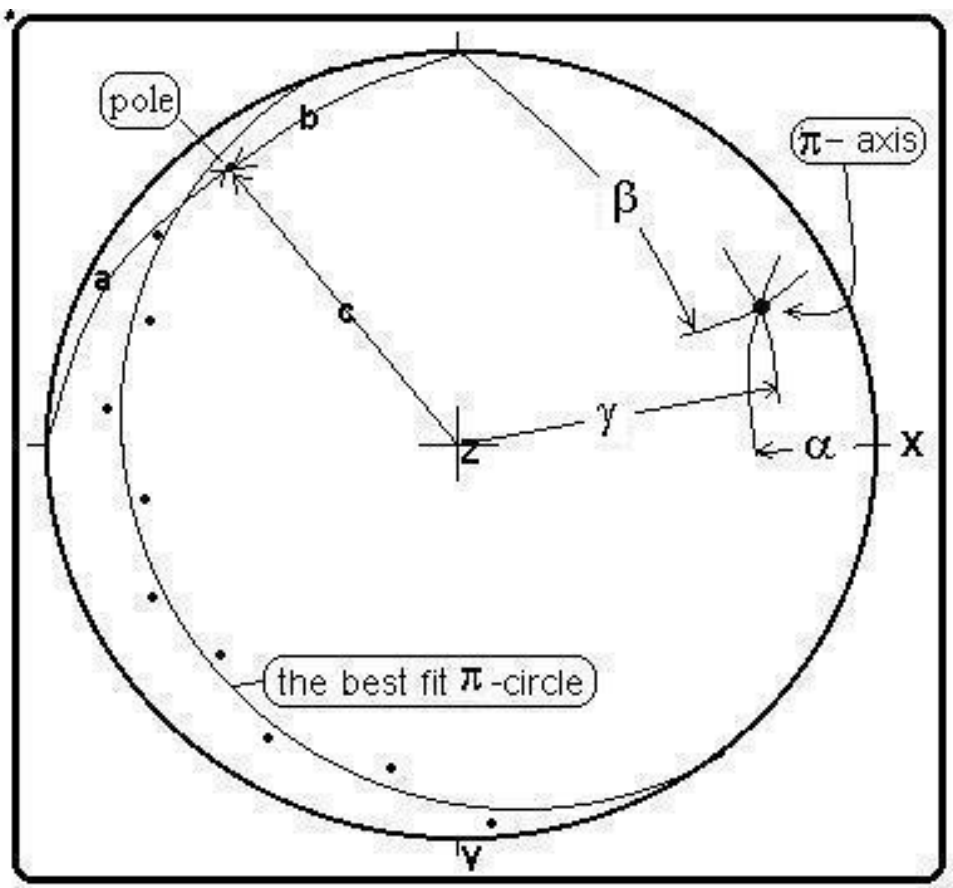

Fig. (6) Calcuation of $\alpha, \beta, \gamma, \mathrm{a}, \mathrm{b}$ and $\mathrm{c}$ and determination of best-fit $\pi$-circle to no. of S-poles (Ramsay,1967) 
Where,

$$
\begin{aligned}
& A=(\Sigma l m \Sigma m n-\Sigma l n \Sigma m 2) /(\Sigma l 2 \Sigma m 2-(\Sigma l m) 2) \\
& B=(\Sigma l m \Sigma l n-\Sigma m n \Sigma l 2) /\left(\sum l 2 \Sigma m 2-(\Sigma l m) 2\right)
\end{aligned}
$$

$\cos a=l, \cos b=m, \cos c=n, \cos \alpha / \cos \gamma=A$ and $\cos \beta / \cos \gamma=B$

Ramsay (1967) derived three equations for determination of $\alpha, \beta$ and $\gamma$. These equations are described below.

Because, $\quad \cos 2 \alpha+\cos 2 \beta+\cos 2 \gamma=1$

And $A=\cos \alpha / \cos \gamma$ and $B=\cos \beta / \cos \gamma$

Therefore $\quad A 2 \operatorname{Cos} 2 \gamma+B 2 \cos 2 \gamma+\cos 2 \gamma=1$

And $\quad \cos 2 \gamma(A 2+B 2+1)=1$

so

$$
\cos 2 \gamma=1 /(A 2+B 2+1)
$$

$$
\cos \gamma=\left(1+A^{2}+B^{2}\right)^{-1 / 2}
$$

Similarly, equations responsible for determining $\alpha$ and $\beta$ were derived.

$$
\begin{aligned}
& \cos \alpha=A\left(1+A^{2}+B^{2}\right)^{-1 / 2} \\
& \cos \beta=B\left(1+A^{2}+B^{2}\right)^{-1 / 2}
\end{aligned}
$$

By the values and signs of these angles the Cartesian coordinate position of $\pi$-axis was found. Fold $\pi$ - circle can be drawn considering this $\pi$-axis normal to it.

\section{4th- Determination of fold geometry:}

Most of the important geometric properties of folds can be determined from this technique. Such properties are fold axis, fold plunge, interlimb angle, fold symmetry, attitude of axial plane and fold cylindricity.

\section{Fold axis:}

The angles $\alpha, \beta$ and $\gamma$ which were calculated in (3rd page 6 ) are used for determining the attitude of fold axis (dip direction / dip amount).

From figure (7),

$$
d p=90-\gamma \text { when } d p \text { is the dip amount of fold axis }
$$

Also from the same figure, the triangle $O A C$ has the right angle $O C A$ and the hypotenuse $O A$ suppose to be unity.

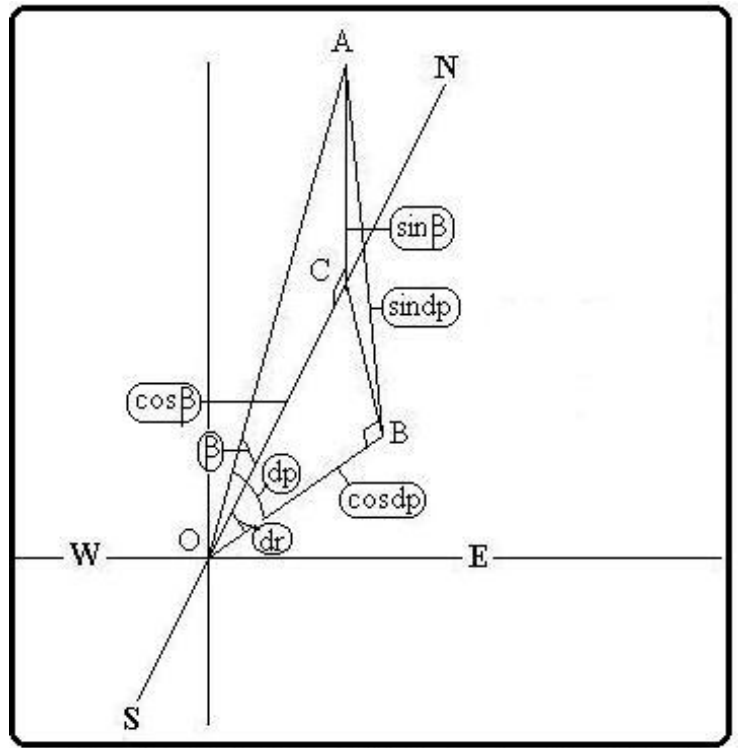

Fig.(7). Conversion of fold axis attitude from directional cosines to dip dirs and dip amounts 


$$
A C=\sin \beta \quad \text { and } \quad O C=\cos \beta
$$

Also in the triangle, $O B A$ is a right angle.

$$
O B=\cos d p \quad \text { and } A B=\sin d p
$$

Whereas in the triangle $A B C$

$$
\begin{aligned}
& A C 2=A B 2+C B 2 \\
& C B=(\sin 2 \beta-\sin 2 d p) 1 / 2
\end{aligned}
$$

In the triangle $O B C$,

$C B 2=O C 2+O B 2-2 . O C . O B \cdot \operatorname{Cos} d r$

$\operatorname{Sin} 2 \beta-\sin 2 d p=\cos 2 \beta \cdot \cos 2 d p-2 \cdot \cos \beta \cdot \cos d p \cdot \cos d r$

2. $\cos \beta . \cos d p . \cos d r=\cos 2 \beta+\cos 2 d p-\sin 2 \beta+\sin 2 d p$

$$
d r=\cos ^{-1}\left[\left(\cos ^{2} \beta+\cos ^{2} d p-\sin ^{2} \beta+\sin ^{2} d p\right) /(2 * \cos \beta * \cos d p)\right]
$$

When $d r$ is the dip direction of fold axis. The signs of the angles $\alpha$ and $\beta$ serve as indicators to show in which quarter of Cartesian coordinate the fold axis was fall (Table 1).

Table $1:$ Signs of the angles $\alpha$ and $\beta$ in each coordinate quarter.

\begin{tabular}{|c|c|c|}
\hline Sign of the angle $\alpha$ & Sign of the angle $\beta$ & Position \\
\hline Positive & Negative & First quarter \\
\hline Positive & Positive & Second quarter \\
\hline Negative & Positive & Third quarter \\
\hline Negative & Negative & Forth quarter \\
\hline
\end{tabular}

If the fold axis falls in the first quarter, $d r$ remains without change. Whereas, if it falls in the second, third and forth quarter, then $90^{\circ}, 180^{\circ}$ and $270^{\circ}$ are added to the angle $d r$ for obtaining its correct dip direction).

Attitude of fold axis $=$ dip direction $(d r) / \operatorname{dip}$ amount $(d p)$

\section{Fold plunge:}

Fold plunge depends upon dip amount of fold axis $(d p)$. When $(d p)$ is equal to zero, the fold is nonplunging. While if $(d p)$ is more than zero, the fold becomes plunging. And increasing of $d p$ angle means increasing of degree of plunging.

$$
\text { Fold Plunge }=d p \text { of fold axis }
$$

\section{Interlimb angle:}

According to this procedure, interlimb angle can be calculated by adding the absolute value of $\gamma 1$ (of the first limb) to the absolute value of $\gamma 2$ (of the second one). The angles $\gamma 1$ and $\gamma^{2}$ are always having negative sign (Fig.4) then it must be considered their absolute values when the interlimb angle was determined. This calculation must be done along a plane perpendicular to the fold axis. Then concentrations of the two limbs must be rotated until the fold axis becomes horizontal and determination of the interlimb angle was done along the N-S vertical plane (Fig. 8). 


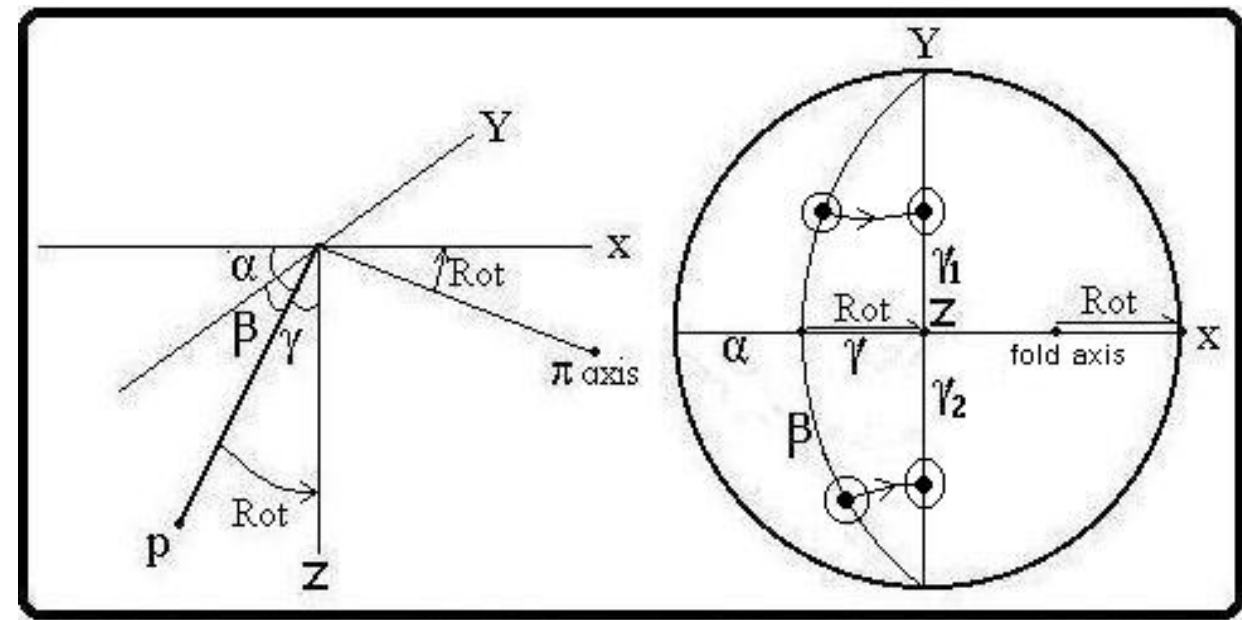

Fig. ( 8 ). Rotation of pole vector until $\pi$-axis becomes horizontal.

$$
\text { Interlimb angle }=\gamma_{\text {limb1 }}+\gamma_{\text {limb2 }}=180-\left(a d p l_{1}+a d p l_{2}\right)
$$

Where adpll and adpl2 are mean dips of the two limbs

\section{Folds symmetry:}

Fold symmetry can be found by comparing adpl1 with adp12 or $\gamma$ limb1 with $\gamma$ limb2. Resultant, if $d p l l$ is equal to $d p l 2$. Then the fold is symmetrical, otherwise it is asymmetrical with the vergency being towards the limb which has greater pole dip angle (dp).

$$
\text { Folds symmetry : } \quad a d p l_{1}<=>a d p l_{2} \underline{O R} \quad \gamma_{\text {limb1 }} \Leftrightarrow>\gamma_{l i m b 2}
$$

\section{Attitude of axial plane:}

This attitude will be possible if the attitude of axial trace is known (Ramsay and Huber, 1987). While if the fold is of parallel type, axial plane can be obtained by joining the bisector of interlimb angle with the fold axis. This is because in the parallel fold the axial plane always bisects the interlimb angle. In this work the axial plane determination was restricted to parallel fold type because other types are more complicated to be processed mathematically.

Axial plane attitude can be represented by its dip amount Apdp and dip direction Apdr.

$$
\text { Apdp }=90-(((\gamma \max +\gamma \min ) / 2)-\gamma \min )
$$

Where $\gamma$ max and $\gamma$ min are dip angles of steep and gentle limbs respectively.

Apdr coincide with the dip direction of gentle limb.

$$
\text { Attitude of axial plane }=\text { Apdp / Apdr }
$$

\section{5th- Determination of fold cylindericity:}

Ramsay and Huber (1987) classified the folds into perfectly cylindrical, cylindrical, sub-cylindrical and non-cylindrical, which were described previously in the introduction (Fig. 2). 
Different natural folds show different properties or different $\pi$-diagram models. And it is very complicated to put a solution for each model. So a simplification was made for putting a general procedure for all these models. This is to revolve and rotate the data (mentioned below) to make a general solution for all the cases and keeping the entire relative geometrical relationships constant with each other but not with the coordinate axes.

\section{Revolving and rotating fold data}

Many authors suggested various methods for rotation of oriented data. Saha (1987) designed a FORTRAN program for rotation of data by transformation matrix. Al-Azzawi and Al-Jumaily (2000) proposed a mathematical procedure for rotation of joint planes relative to bedding rotation by trigonometric method.

For the sake of applying this idea, two stages are used. Firstly, revolving of data, horizonally, until direction of $\pi$-axis coincides with east direction of stereonet. This is done by adding $(90-d r)$ when $d r$ less than $90^{\circ}$, and subtracting $(d r-90)$ when $d r$ more than $90^{\circ}$ to or from the angle $d r$.

$$
\begin{gathered}
\text { If } d r<90 \text { then } d r=d r+(90-d r) \text { clockwise rotation } \\
\text { Wheras, if } d r>90 \text { then } d r=d r-(d r-90) \text { anticlockwise }
\end{gathered}
$$

Secondly, rotation of all data around $Y$ coordinate axis ( $N-S$ line in the stereonet) until $\pi$-axis becomes horizontal; it means rotation angle $(R)=d p$ of $\pi$-axis (Fig. 8). When $\pi$-axis rotated by the angle $R, \pi$-circle became vertical plane. This is because $\pi$ axis is always perpendiocular to the plane containing bedding S-poles ( $\pi$-circle). This rotation can be done by transformation matrix. Many authors such as Arfken (1970) and Saha (1987) described this method. And it is summarizes here by the followings:

1- Determination of $L, M \& N$ components for each S-pole vector before rotation.

$$
L=\cos d p \cdot \sin d r, \quad M=\cos d p \cdot \cos d r \quad \text { and } \quad N=\sin d p
$$

2- Multiplication of the components $L, M \& N$ by the transformational matrix that is responsible for rotation of vectors anticlockwise around $Y$-axis and through an angle $R$.

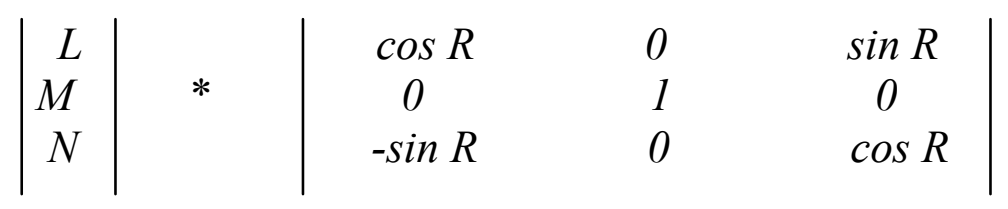

The resultant are new $L, M \& N$ components ( after rotation)which are used to determine the direction $d r$ and dip angle $d p$ of a pole vector.

$$
d p=\sin ^{-1} N_{\text {new }} \text { and } d r=\sin ^{-1}\left(L_{\text {new }} / \cos d p\right) \text { or } d r=\cos ^{-1}\left(M_{\text {new }} / \cos d p\right)
$$

Mathematically, this fold classification could not be applied without revolving and rotating data (as it mentioned above). Rotating all data until $\pi$-axis becomes horizontal standardize all natural cases in into one form. Figure (9) shows the rotated state of Figure (2) which responsible for this classification. Figure (9) can be used to plot the revolved and rotated bedding S-poles of any fold and to find the type of this fold according to its cylindricity. 


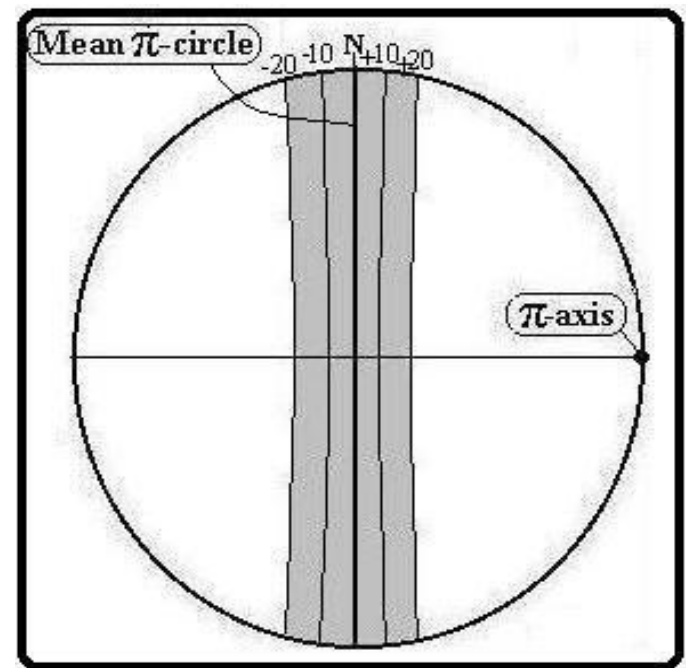

Fig.(9). Rotation of Fig.(2) untill $\pi$-axis become horizontal.

Ramsay and Huber (1987) suggested limits for difining fold cylindricity (Fig. 2). These limits are \pm 10 and \pm 20 around $\pi$-circle of perfect cylindrical fold. These limits were divided the stereonet into fields; each field represents one of fold types. Figure (9) showed these limits after revolution and rotation. Empirically, the present author derived mathematical equations to deal with these limits during the present technique. And using Lagrangian interpolation method mentioned in (Al-Azzawi, 2004) does this. For more explanation, the author exhibited curves shown in figure (10) representing these limits

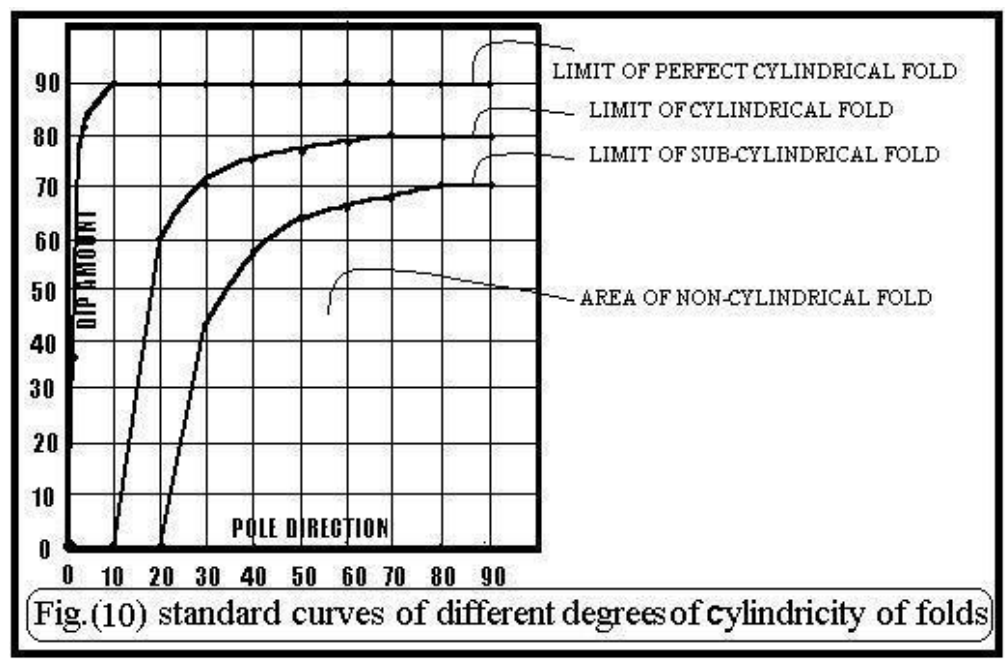

S-pole directions of stereonet normally range from $1^{\circ}$ to $360^{\circ}$. So that, direction of each S-pole can be tested and determined in which field it fall. Counting of these poles and obtaining the percentage of each field was done. Then the fold can be classifying as in the followings:

1- If all S-poles fall on the plane of perfectly cylindrical ( $\pi$-circle) (Fig. 11), then it is called perfectly cylindrical fold.

2- If $90 \%$ of S-poles fall between plane-10 and plane+10 around the mean $\pi$-circle (Fig.9) or on and above the standard curve of cylindrical fold (Fig. 10), then the fold named cylindrical type. 
3- If $90 \%$ of them fall between plane- 20 and plane+20 (Fig.9) or on and above the standard curve of sub-cylindrical fold (Fig.10), the fold classified as sub-cylindrical type.

4- Otherwise or when more than $10 \%$ of the S-poles lie outside plane- 20 and plane +20 (Fig.9) or fall below the standard curve of sub-cylindrical fold (Fig.10), the fold becomes non-cylindrical type.

So, mathematically or by computer programming, the number of bedding S-poles that fall between these limits can be determined.

The procedure for analyzing fold was designed in GWBASIC computer program called FOLDPI (see the Appendix)

\section{Tested sample:}

Data for checking the validity of this technique has been taken from Sinjar Anticline. Al-Azzawi (1982) studied this anticline through three traverses. They named Gaulat, Sinjar and Jeribi. The first one was used for this test. The anticline in this traverse is, stratigraphically, comprise Shiranish formation of Upper Cretaceous age (the older formation). And it is followed by Aliji Fn. (Paleocene -L. Eocene), Jaddala Fn (Middle to Upper Eocene), Avana Fn. (M. to U. Eocene), Euphrates Fn. (L. Miocene), Serigakni Fn. (L. Miocene), Jeribe Fn. (L. Miocene), Alfatha Fn. (M. Miocene) and Injana Fn. (U. Miocene), (Al-Azzawi, 1982; Numan and Al-Azzawi, 2002). Tested data was taken from Serikagni Fn. (both Sinjar and Gaulat traverse) and analyzed graphically by $\pi$-diagram.

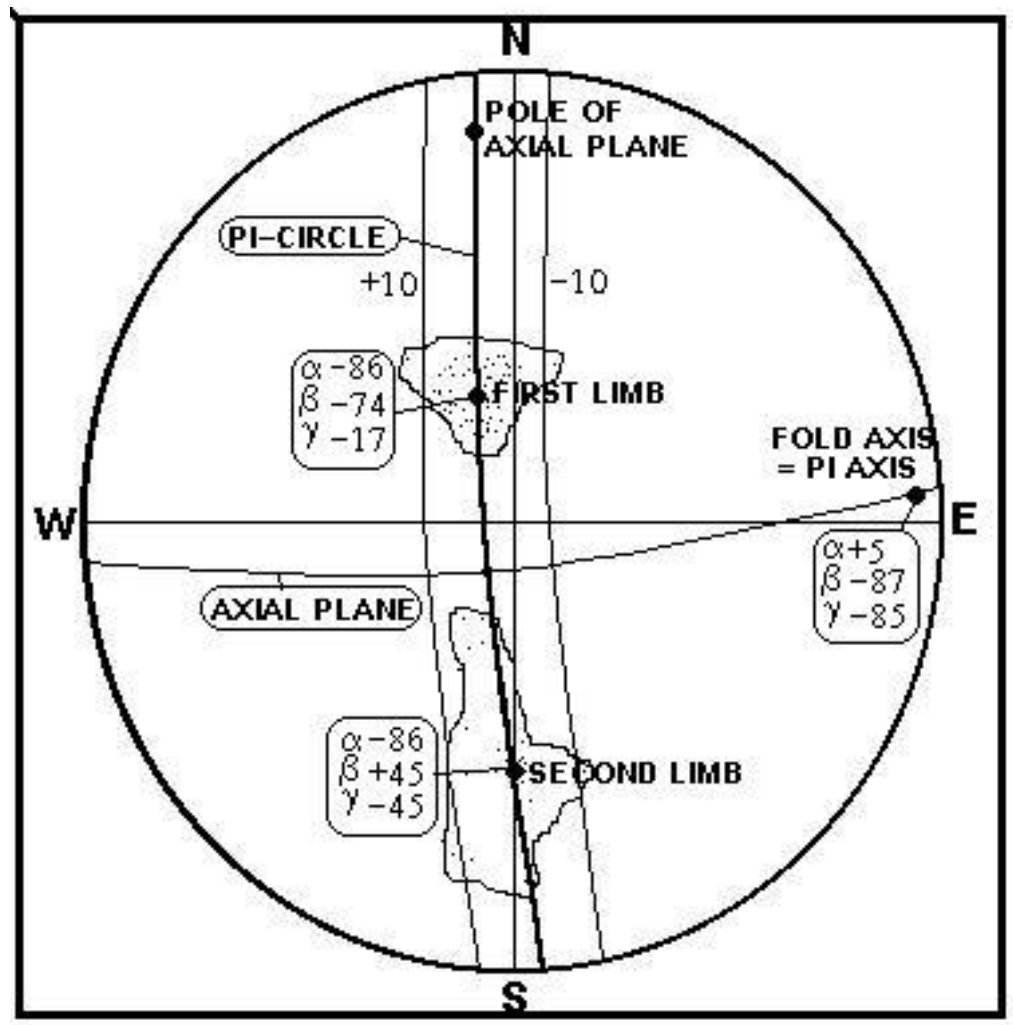

Fig.(11) $\pi$-Diagram of Sinjar Anticline, data was taken from Serikaani Fn. (Modified from Numan and AI-Azzawi,2002) 
Consequently, the geometric properties of this fold are shown in a $\pi$-diagram of Figure (11). This Figure showed that the mean pole attitudes of first and second limb are 340/74 and $182 / 43$, attitude of fold axis is $087 / 5$, it is asymmetrical fold with $\mathrm{N}$ vergency, plunging fold with 7 degrees, the interlimb angle is $120^{\circ}$, dip amount of axial plane is $76^{\circ}$ toward SE and more than $90 \%$ of bedding S-poles are fall within \pm 10 around the mean $\pi$ circle then the fold classified as cylindrical fold. A computer program output for this analysis is exhibited in Figure (12) that shows not only encouraging result but it is more easy, fast and accurate than the graphical method specially when it done by computer scheme.

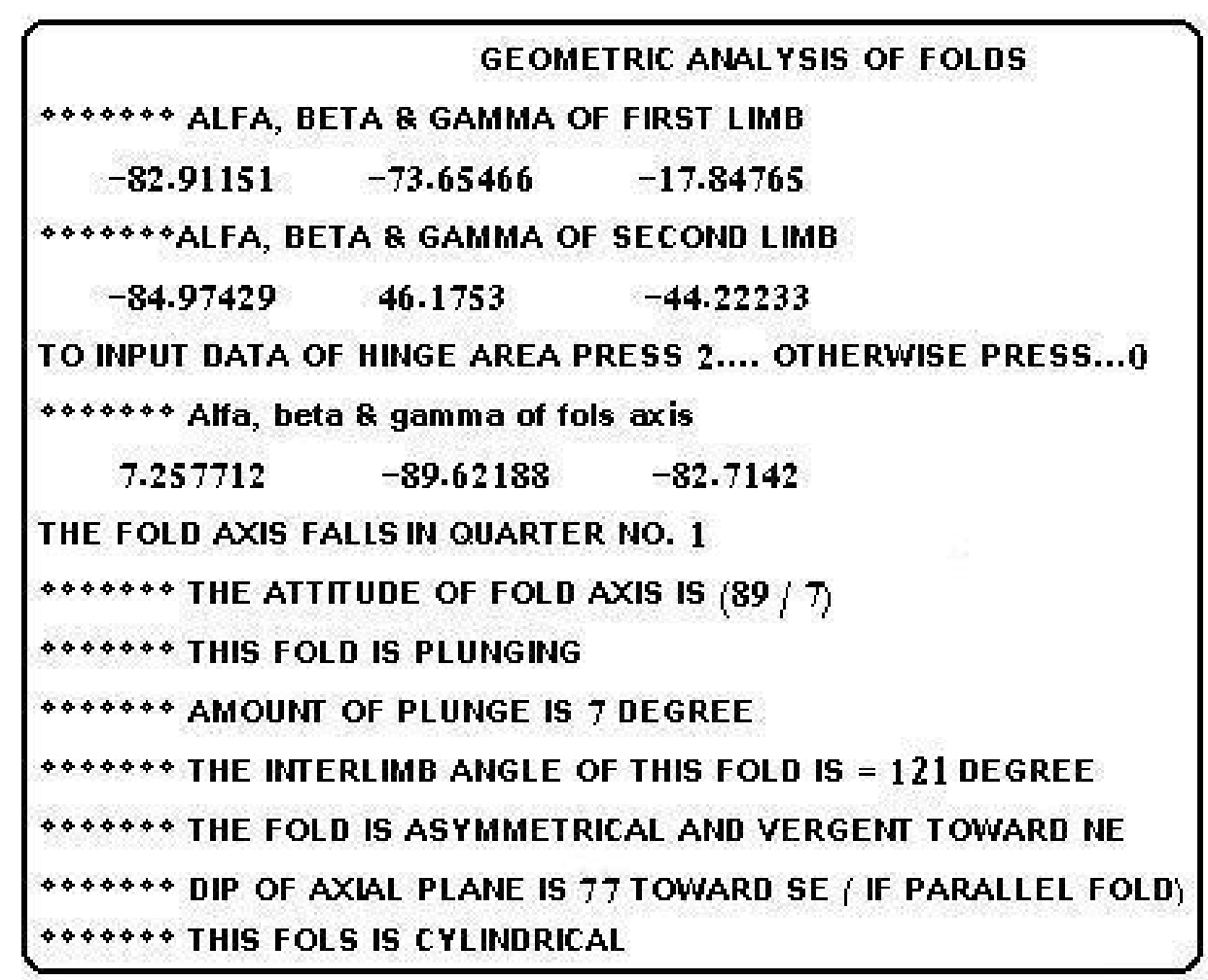

Fig.(12) Output of the program FOLDPI showing the geometric analysis of Sinjar Anticline.

\section{REFERENCES}

Al-Azzawi, N.K., 1982. Comparative Study of The Tectonic Styles of Folds in Three Areas in the Simple Folded Zone of Iraq, Unpublished M. Sc. Thesis, University of Mosul.

Al-Azzawi, N.K. and Al-Jumaily, M.Q. 2000. Geometric Classification of Joints Using Computer Program, Raf. Jour. Sci., Vol.11, No.2, pp. 50-64.

Al-Azzawi, N.K., 2004. Determination of Fold Profiles and Fold Functions, a Mathematical Approach. Iraqi Jour. of Earth Science, Vol. 4, No.1, pp. 22-35.

Arfken, G., 1970. Mathematical Methods for Physicists, Academic Press, second addition, New York and London, 815 P.

Bengston, C.A., 1980, Structural uses of tangent diagrams, Geology, V. 8, No. 12, pp. 599-602. 
Fleuty, M.J., 1964. The Description of Folds, Proc. Geol. Assoc.London, Vol.75, pp.461-492.

Numan, N.M.S. and Al-Azzawi, N.K., 2002. Progressive Versus Paroxysmal Alpine Folding in Sinjar Anticline Northwest Iraq, Iraqi Jour. Of Earth Science, Vol. 2, No. 2, pp.59-69.

Ramsay, J.G. and Huber, M.I., 1987. The techniques of modern structural geology: V.2, folds and Fractures, Academic Press, London, UK, 700p.

Ramsay, J.G., 1967. Folding and fracturing of rocks, McGraw Hill, New York, 568.

Saha, D., 1987. SPIN8: A FORTRAN 77 Program for Automated Rotation of Poles, Computers and Geosciences, Vol.13, No. 3, pp. 235-254. 
A Mathematical Technique for Analyzing Folds...

\section{APPENDIX}

10 REM

FOLDPI

20 REM PROGGRAM FOR ANALIZING FOLDS BY NEW MATHEMATICAL TECHNIQUE

30 REM DEPENDING ON THE PI- DIAGRAM PRINCIPALS . WRITTEN BY DR. NABEEL K .

40 REM AL -AZZAWI, JONE ,2005. DEPARTEMENT OF GEOIOGY/UNIVERSITY OF MOSUL.

50 CLS.

60 PRINT

70 PRINT “

GEOMETRIC ANALYSIS OF FOLDS “

80 PRIN “

90 PRINT

$100 \mathrm{~N} 1=50$

$110 \mathrm{~N} 2=15$

$120 \mathrm{~N} 3=0$

$130 \mathrm{~K}=\mathrm{N} 1+\mathrm{N} 2$

$140 \mathrm{M}=\mathrm{N} 1+\mathrm{N} 2+\mathrm{N} 3$

150 DIM DS(M), DPL(M), DR(M), DR1(M), DR2(M), DR3(M), DRR(M), DP(M), DP1(M), DP2(M), DPP(M), CDR(M), ALFA(M), BETA(M), GAMA(M), OFIE1(M), OFIE2(M), COSALF(M), COSBET(M), COSGAM(M), $\mathrm{X}(10), \mathrm{FX}(10), \mathrm{LU}(10), \mathrm{LD}(10)$

$160 \mathrm{CINDY}=1$

170 REM INPUT DATA OF BEDDING PLANES AS STRIKE DIRECTIONS / DIP AMOUNTS.

180 IF CINDY $=1$ THEN PRINT"*********ALFA, BETA \& GAMMA OF FIRST LIMB"

190 IF CINDY=2 THEN PRINT"*********ALFA, BETA \& GAMMA OF SECOND LIMB"

200 IF CINDY=3 THEN PRINT"*********ALFA, BETA \& GAMMA OF HINGE AREA"

210 ON CINDY GOTO 220,230,240

$220 \mathrm{~N}=\mathrm{N} 1:$ GOTO 250

$230 \mathrm{~N}=\mathrm{N} 2:$ GOTO 250

$240 \mathrm{~N}=\mathrm{N} 3$

$250 \mathrm{SDPL}=0$

$260 \mathrm{SDDR}=0$

270 FOR I $=1$ TO N

280 READ DS(I), DPL(I)

$290 \mathrm{SDPL}=\mathrm{SDPL}+\mathrm{DPL}(\mathrm{I})$

$300 \mathrm{DDR}=\mathrm{DS}(\mathrm{I})-90$

$310 \mathrm{SDDR}=\mathrm{SDDR}+\mathrm{DDR}$

320 NEXT I

330 DATA 234,16, 240,17, 246,15, 242,18, 240,18, 242, 17, 260,21,242,18, 252,20, 240,23,248, 23,15, $250,13,236,13,250,10,270,18,248,20$

340 DATA $236,19,240,18,242,12,256,12,250,10,244,12,250,14,236,16,240,20,260,18,268,20,250$, $18,264,21,252,18,264,20,240,20$

350 DATA 230, 20,240,20, 260, 20, 286,22,242, 20, 232, 22, 250, 23, 230,32,228, 30,230,18, 252, 20, 254,12,18, $248,15,258,20,258,15$

360 DATA 100, 25, 110, 28, 90, 60, 89, 69, 100, 60, 80, 42, 74, 43, 90, 42, 100, 37, 87,45,100,45, 88, 49, 94, 42, $98,34,79,45$

370 ADPL $(\mathrm{CINDY})=\operatorname{INT}(\mathrm{SDPL} / \mathrm{N})$

380 ADDR $($ CINDY $)=\operatorname{INT}($ SDDR/N)

$390 \mathrm{IF}$ ADDR $(\mathrm{CINDY})<0$ THEN ADDR $(\mathrm{CINDY})=360-\mathrm{ADDR}(\mathrm{CINDY})$

$400 \mathrm{SDR}=0$

410 FOR I $=1$ TO N

420 REM $D R$ AND $D P$ ARE DIP DIRECTION AND DIP AMOUNT OF S-POLE,

430 REM WHERE $C D R$ IS THE COMLIMENTARY ANGLE OF $D R$.

$440 \mathrm{DR}(\mathrm{I})=90+\mathrm{DS}(\mathrm{I}): \mathrm{DP}(\mathrm{I})=90-\mathrm{DPL}(\mathrm{I}): \mathrm{IF} \mathrm{DR}(\mathrm{I})>360$ THEN DR(I) $=\mathrm{DR}(\mathrm{I})-360$

$450 \mathrm{SDR}=\mathrm{SDR}+\mathrm{DR}(\mathrm{I})$

460 REM THE THREE STATEMENTS BELOW ARE TO PUT ALL READINGS (OF 2 LIMBS AND HINGEA REA) IN ONE ARRY.

470IF CINDY $=1$ THEN DR2(I) $=$ DR(I) $:$ DP2(I) $=$ DP(I)

$480 \mathrm{IF}$ CINDY $=2$ THEN DR2 $(\mathrm{I}+\mathrm{N} 1)=\mathrm{DR}(\mathrm{I}): \mathrm{DP} 2(\mathrm{I}+\mathrm{N} 1)=\mathrm{DP}(\mathrm{I})$

$490 \mathrm{IF}$ CINDY $=3$ THEN DR2 $(\mathrm{I}+\mathrm{K})=\mathrm{DR}(\mathrm{I}): \mathrm{DP} 2(\mathrm{I}+\mathrm{K})=\mathrm{DPI}$

500 IF DR $(\mathrm{I})<=90$ THEN DR 1 ( I $)=$ DR $(\mathrm{I})$

510 IF DR ( I ) $>90$ AND DR ( I ) $<=180$ THEN DR1 ( I )=DR ( I ) -90 
520 IF DR ( I ) $>180$ AND DR ( I $<=270$ THEN DR1 ( I $)=$ DR ( I $)-180$

$530 \mathrm{IF}$ DR ( I ) $>270$ AND DR ( I $)<=360$ THEN DR 1 ( I $)=$ DR ( I $)-270$

$540 \mathrm{CDR}(\mathrm{I})=90-\mathrm{DR} 1(\mathrm{I})$

550 DR1 ( I ) $=$ DR1 ( I ) * $3.132857 / 180$

$560 \mathrm{DP}(\mathrm{I})=\mathrm{DP}(\mathrm{I}) * 3.142857 / 180: \mathrm{CDR}(\mathrm{I})=\mathrm{CDR}(\mathrm{I}) * 3.142857 / 180$

570 NEXT I

$580 \mathrm{ADR}(\mathrm{CINDY})=\mathrm{SDR} / \mathrm{N}$

590 REM DETERMINATION OF DIRECTIONAL COSINES: THERE ARE FOUR CASES.

600 REM GAMMA=90-DP WITH -VE SIGN.

610 FOR I $=1$ TO N

620 GAMA(I) $=90-\mathrm{DP}(\mathrm{I}) * 180 / 3.142857$

630 GAMA $(\mathrm{I})=$ GAMA $(\mathrm{I}) * 3.142857 / 180$

640 IF GAMA(I) $>0$ THEN GAMA(I) $=0-$ GAMA(I)

650 OFIE1 $(\mathrm{I})=\left((\operatorname{COS}(\mathrm{CDR}(\mathrm{I})))^{\wedge} 2 *(\operatorname{COS}(\mathrm{DP}(\mathrm{I})))^{\wedge} 2+1-(\operatorname{SIN}(\mathrm{DP}(\mathrm{I})))^{\wedge} 2-(\operatorname{COS}(\mathrm{DP}(\mathrm{I})))^{\wedge} 2\right.$

$* \operatorname{SIN}(\operatorname{DR} 1(\mathrm{I}))) \wedge 2) /(2 * \operatorname{COS}(\mathrm{DR} 1(\mathrm{I})) * \operatorname{COS}(\mathrm{DP}(\mathrm{I})))$

670 IF DR(I) $>90$ THEN 750

$680 \operatorname{COSALF}(\mathrm{I})=$ OFIE $1(\mathrm{I})$

690 COSBET $(\mathrm{I})=$ OFIE2 $(\mathrm{I})$

$700 \operatorname{ALFA}(\mathrm{I})=\operatorname{ATN}\left(\operatorname{SQR}\left(1-(\operatorname{OFIE} 1(\mathrm{I}))^{\wedge} 2\right) / \operatorname{OFIE} 1(\mathrm{I})\right)$

710 BETA(I) $=$ ATN $\left(\operatorname{SQR}\left(1-(\text { OFIE2(I) })^{\wedge} 2\right) /\right.$ OFIE2(I))

720 IF ALFA(I) $<0$ THEN ALFA(I) $=0$ - ALFA(I)

730 IF BETA(I) $>0$ THEN BETA $(\mathrm{I})=0-$ BETA(I)

740 GOTO 980

750 IF DR(I) > 180 THEN 830

760 COSALF $(\mathrm{I})=$ OFIE2 $(\mathrm{I})$

770 COSBET $(\mathrm{I})=$ OFIE $1(\mathrm{I})$

780 ALFA(I) $=\operatorname{ATN}(\operatorname{SQR}(1-($ OFIE2(I) $) \wedge 2) /$ OFIE2(I) $)$

790 BETA(I) $=\operatorname{ATN}(\operatorname{SQR}(1-($ OFIE1(I) $) \wedge 2) /$ OFIE1(I))

$800 \mathrm{IF}$ ALFA $(\mathrm{I})<0$ THEN ALFA $(\mathrm{I})=\operatorname{ALFA}(\mathrm{I}) *(-1)$

810 IF BETA $(\mathrm{I})<0$ THEN BETA $(\mathrm{I})=\operatorname{BETA}(\mathrm{I}) *(-1)$

820 GOTO 980

830 IF DR(I) $>270$ THEN 910

$840 \operatorname{COSALF}(\mathrm{I})=$ OFIE $1(\mathrm{I})$

$850 \operatorname{COSBET}(\mathrm{I})=$ OFIE2 $(\mathrm{I})$

860 ALFA(I) $=\operatorname{ATN}\left(\operatorname{SQR}\left(1-(\text { OFIE1(I) })^{\wedge} 2\right) /\right.$ OFIE1(I) $)$

870 BETA $(\mathrm{I})=$ ATN $)$ SQR $\left(1-\left(\right.\right.$ OFIE2 $\left.(\mathrm{I})^{\wedge} 2\right) /$ OFIE2(I)

880 IF ALFA(I) $>0$ THEN ALFA(I) $=0-\operatorname{ALFA}(\mathrm{I})$

890 IF BETA $(\mathrm{I})<0$ THEN BETA $(\mathrm{I})=0$ - BETA(I)

900 GOTO 980

910 REM WHEN DR MORE THAN 270 .

$920 \operatorname{COSALF}(\mathrm{I})=$ OFIE2 $(\mathrm{I})$

$930 \operatorname{COSBET}(\mathrm{I})=$ OFIE $1(\mathrm{I})$

$940 \operatorname{ALFA}(\mathrm{I})=\operatorname{ATN}\left(\mathrm{SQR}\left(1-(\mathrm{OFIE} 2(\mathrm{I}))^{\wedge} 2\right) /\right.$ OFIE2(I))

$950 \operatorname{BETA}(\mathrm{I})=\operatorname{ATN}\left(\operatorname{SQR}\left(1-(\mathrm{OFIE} 1(\mathrm{I}))^{\wedge} 2\right) / \operatorname{OFIE} 1(\mathrm{I})\right)$

960 IF ALFA(I) $>0$ THEN ALFA(I) $=0$ - ALFA(I)

970 IF BETA9i0 $>0$ THEN BETA(I) $=0$ - BETA(I)

980 NEXT I

990 REM DETERMINING THE SUMMATION OF COSALF, COSBET \&COSGAM

$1000 \mathrm{SCOSALF}=0:$ SCOSBET $=0:$ SCOSGAM $=0$

1010 FOR I $=1$ TO N

$1020 \operatorname{COSGAM}(\mathrm{I})=\operatorname{COS}(\mathrm{GAMA}(\mathrm{I}))$

$1030 \mathrm{SCOSALF}=\mathrm{SCOSALF}+\operatorname{COSALF}(\mathrm{I})$

$1040 \mathrm{SCOSBET}=\mathrm{SCOS}$ BET + COSBET $(\mathrm{I})$

1050 SCOSGAM $=$ SCOSGAM + COSGAM $(\mathrm{I})$

1060 NEXT I

1070 REM DETERMINATION OF UNIMODAL POLE DISTRIBUTION BY SUMMING METHOD. COSALF, COSBET \& COSGAM ARE DIRECTIONAL COSINES OF THE MEAN OF POLE VECTORS.

1080 TVS $=\left((\text { SCOSALF })^{\wedge} 2+(\text { SCOSBET })^{\wedge} 2+(\operatorname{SCOSGAM})^{\wedge} 2\right)^{\wedge}(1 / 2)$

1090 COSA $($ CINDY $)=$ SCOSALF $/$ TVS

$1100 \operatorname{COSB}(\mathrm{CINDY})=\mathrm{SCOSBET} / \mathrm{TVS}$

$1110 \operatorname{COSC}(\mathrm{CINDY})=\mathrm{SCOSGAM} / \mathrm{TVS}$ 
$1120 \mathrm{~A}(\mathrm{CINDY})=\mathrm{ATN}(\mathrm{SQR}(1-\operatorname{COSA}(\mathrm{CINDY}) \wedge 2 / \mathrm{COSA}(\mathrm{CINDY}))$

$1130 \mathrm{~B}(\mathrm{CINDY})=\operatorname{ATN}(\operatorname{SQR}(1-\operatorname{COSB}(\mathrm{CINDY}) \wedge 2 / \operatorname{COSB}(\mathrm{CINDY}))$

$1140 \mathrm{C}(\mathrm{CINDY})=\operatorname{ATN}(\operatorname{SQR}(1-\operatorname{COSC}(\mathrm{CINDY}) \wedge 2 / \mathrm{COSC}(\mathrm{CINDY}))$

1150 PRINT “ THE DIR. OF LIMB NO. “ ; CINDY; “ IS “ ; ADR(CINDY)

1160 IF ADR(CINDY) $<=90$ THEN 1200

1170 IF ADR(CINDY) $<=180$ THEN 1210

1180 IF ADR(CINDY) $<=270$ THEN 1220

1190 ADR(CINDY) $>270$ THEN

$1200 \mathrm{~A}(\mathrm{CINDY})=\mathrm{ABS}(\mathrm{A}(\mathrm{CINDY})): \mathrm{B}(\mathrm{CINDY})=\mathrm{ABS}(\mathrm{B}(\mathrm{CINDY})) *(-1): \mathrm{C}(\mathrm{CINDY})=\mathrm{ABS}(\mathrm{C}(\mathrm{CINDY}))$ * $(-1)$ : GOTO 1240

$1210 \mathrm{~A}(\mathrm{CINDY})=\mathrm{ABS}(\mathrm{A}(\mathrm{CINDY})): \mathrm{B}(\mathrm{CINDY})=\mathrm{ABS}(\mathrm{B}(\mathrm{CINDY})): \mathrm{C}(\mathrm{CINDY})=\mathrm{ABS}(\mathrm{C}(\mathrm{CINDY}) *(-1)$ : GOTO 1240

$1220 \mathrm{~A}(\mathrm{CINDY})=\mathrm{ABS}(\mathrm{A}(\mathrm{CINDY}) *(-1): \mathrm{B}(\mathrm{CINDY})=\mathrm{ABS}(\mathrm{B}(\mathrm{CINDY})): \mathrm{C}(\mathrm{CINDY})=\mathrm{ABS}(\mathrm{C}(\mathrm{CINDY})) *$ $(-1)$ : GOTO 1240

$1230 \mathrm{~A}(\mathrm{CINDY})=\mathrm{ABS}(\mathrm{A}(\mathrm{CINDY}))(-1): \mathrm{B}(\mathrm{CINDY})=\mathrm{ABS}(\mathrm{B}(\mathrm{CINDY})) *(-1): \mathrm{C}(\mathrm{CINDY})=$ $\mathrm{ABS}(\mathrm{C}(\mathrm{CINDY})) *(-1)$

$1240 \mathrm{~A} 1(\mathrm{CINDY})=\mathrm{A}(\mathrm{CINDY}) * 180 / 3.142857: \mathrm{B} 1(\mathrm{CINDY})=\mathrm{B}(\mathrm{CINDY}) * 180 / 3.142857: \mathrm{C} 1(\mathrm{CINDY})$ $=\mathrm{C}(\mathrm{CINDY}) * 180 / 3.142857$

1250 PRINT A1(CINDY),B1(CINDY),C1(CINDY),CINDY

$1260 \mathrm{IF}$ CINDY $=1$ THEN CINDY $=\mathrm{CINDY}+1:$ GOTO 170

1270 IF CINDY $=2$ THEN INPUT “TO INPUT DATA OF HINGE AREA PRESS ..2 OTHERWISE PRESS ..0"; XXX: IF XXX=2 THEN CINDY = CINDY + 1: GOTO 170

1280 REM DETERMINATION OF BEST -FIT PI-CIRCLE OF FOLD.

$1290 \mathrm{SLM}=\mathrm{SMN}=\mathrm{SLN}=\mathrm{SM} 2=\mathrm{SL} 2=0$

1300 FOR I $=1$ TO 2

$1310 \mathrm{~L}(\mathrm{I})=\cos (\mathrm{A}(\mathrm{I})): \mathrm{M}(\mathrm{I})=\cos (\mathrm{B}(\mathrm{I})): \mathrm{N}(\mathrm{I})=\cos (\mathrm{C}(\mathrm{I}))$

1320 IF A1(I) $>0$ THEN L(I) $=\mathrm{L}(\mathrm{I}) *(-1)$

$1330 \mathrm{IFB} 1(\mathrm{I})>0$ THEN $\mathrm{M}(\mathrm{I})=\mathrm{M}(\mathrm{I}) *(-1)$

1340 IF $\mathrm{C} 1(\mathrm{I})<0$ THEN N(I) $=\mathrm{N}(\mathrm{I}) *(-1)$

$1350 \mathrm{SLM}=\mathrm{SLM}+\mathrm{L}(\mathrm{I}) * \mathrm{M}(\mathrm{I})$

$1360 \mathrm{SMN}=\mathrm{SMN}+\mathrm{M}(\mathrm{I}) * \mathrm{~N}(\mathrm{I})$

$1370 \mathrm{SLN}=\mathrm{SLN}+\mathrm{L}(\mathrm{I}) * \mathrm{~N}(\mathrm{I})$

$1380 \mathrm{SL} 2=\mathrm{SL} 2+(\mathrm{L}(\mathrm{I}))^{\wedge} 2$

$1390 \mathrm{SM} 2=\mathrm{SM} 2+(\mathrm{M}(\mathrm{I}))^{\wedge} 2$

1400 NEXT I

$1410 \mathrm{AA}=\left(\mathrm{SLM}^{*} \mathrm{SMN}-\mathrm{SLN} * \mathrm{SM} 2 /(\mathrm{SL} 2 * \mathrm{SM} 2-(\mathrm{SLM}) \wedge 2)\right.$

$1420 \mathrm{BB}=(\mathrm{SLM} * \mathrm{SLN}-\mathrm{SMN} * \mathrm{SL} 2) /\left(\mathrm{SL} 2 \mathrm{SL} 2 * \mathrm{SM} 2-(\mathrm{SLM})^{\wedge} 2\right)$

$1430 \mathrm{COSALF} 1=\mathrm{AA}^{*}\left(1+\mathrm{AA}^{\wedge} 2+\mathrm{BB}^{\wedge} 2\right)^{\wedge}(-1 / 2)$

$1440 \mathrm{COSBET} 1=\mathrm{BB}^{*}\left(1+\mathrm{AA}^{\wedge} 2+\mathrm{BB}^{\wedge} 2\right)^{\wedge}(-1 / 2)$

$\left.1450 \mathrm{COSGAM} 1=1+\mathrm{AA}^{\wedge} 2+\mathrm{BB}^{\wedge} 2\right)^{\wedge}(-1 / 2)$

$1460 \mathrm{ALFA} 1=\operatorname{ATN}\left(\operatorname{SQR}\left(1-(\operatorname{COSALF} 1)^{\wedge} 2\right) / \operatorname{COSALF} 1\right)$

$1470 \mathrm{BETA} 1=\operatorname{ATN}\left(\operatorname{SQR}\left(1-(\operatorname{COSBET} 1)^{\wedge} 2\right) / \mathrm{COSBET} 1\right)$

$1480 \mathrm{GAMA} 1=\mathrm{ATN}\left(\mathrm{SQR}\left(1-(\mathrm{COSGAM} 1)^{\wedge} 2\right) / \mathrm{COSGAM} 1\right)$

1490 IF GAMA1 $>0$ THEN 1530

1500 GAMA $1=$ GAMA $1 *(-1)$

1510 BETA $1=$ BETA $1 *(-1)$

1520 ALFA $1=$ ALFA $1 *(-1)$

1530 ALFA $2=$ ALFA $1 * 180 / 3.142857$

1540 BETA2 $=$ BETA $1 * 180 / 3.142857$

1550 GAMA2 $=$ GAMA $1 * 180 / 3.142857$

1560 PRINT “********ALFA, BETA \& GAMA OF FOLD AXIS”

1670 PRINT ALFA2,BETA2,GAMA2

1580 REM THIS ALFA,BETA AND GAMMA ARE OF PI-AXIS THAT IS NORMAL TO PI-CIRCLE 1590 REM IF ALFA IS +VE \& BETA -VE ------PI-AXIS FALL IN THE FIRST QUARTER.

1600 REM IF ALFA IS +VE \& BETA +VE ------PI-AXIS FALL IN THE SECOND QUARTER

1610 REM IF ALFA IS -VE \& BETA -VE ------PI-AXIS FALL IN THE THIRD QUARTER

1620 REM IF ALFA IS -VE \& BETA -VE ------PI-AXIS FALL IN THE FIRST QUARTER

1630 REM DP (HERE) IS DIP OF PI-AXIS AND DR IS ITS DIP DIRECTION.

$1640 \mathrm{DP}=90-\mathrm{ABS}($ GAMA2)

$1650 \mathrm{DP} 1=\mathrm{DP} * 3.142857 / 180$ 
1660 AXIS $=\left((\operatorname{COS}(\text { ALFA1 }))^{\wedge} 2+(\operatorname{COS}(\mathrm{DP} 1))^{\wedge} 2-(\operatorname{SIN}(\mathrm{ALFA} 1))^{\wedge} 2+(\operatorname{SIN}(\mathrm{DP} 1))^{\wedge} 2\right) /(2 * \operatorname{COS}(\mathrm{ALFA} 1)$

$* \operatorname{COS}(\mathrm{DP} 1))$

$1670 \mathrm{DR}=\mathrm{ATN}(\mathrm{SQR}(\mathrm{ABS}(1-\operatorname{AXIS} \wedge 2)) / \mathrm{AXIS})$

$1680 \mathrm{DR}=\mathrm{DR} 83,142857$

1690 IF ALFA1 $>0$ AND BETA $1<0$ THEN QR=1

1700 IF ALFA $1>0$ AND BETA1 $>0$ THEN QR=2

1710 IF ALFA $1<0$ AND BETA $1<0$ THEN QR=3

1720 IF ALFA $1<0$ AND BETA $1<0$ THEN QR=4

$1730 \mathrm{IF} \mathrm{QR}=1$ THEN DR=90-DR

$1750 \mathrm{IF} \mathrm{QR}=2$ THEN DR $=\mathrm{DR}+90$

$1760 \mathrm{IF} \mathrm{QR}=3$ THEN DR=DR +180

$1770 \mathrm{IF}$ QR $=4$ THEN DR $=\mathrm{DR}+270$

1780 PRINT

1790 PRINT “THE FOLD AXIS IS FALL IN THE QUARTER NO.”;QR

1800 REM DETERMINING THE ATTITUDE OF FOLD AXIS

1810 REM

1820 PRINT"******** THE ATTITUDE OF FOLD AXIS IS (“;INT(DR);"/";INT(DP)")"

1830 REM DETERMINATION OF FOLD PLUNGE

1840 REM-

1850 IF DP=0 THEN PLUNGE $\$=" N O N P L U N G I N G "$

1860 IF DP $>0$ THEN PLUNGE $\$=$ " PLUNGING"

1870 PRINT"********THIS FOLD IS";PLUNGE\$

1880 PRINT"********AMOUNT OF PLUNGING IS";INT(DP);”DEGREE"

1890 REM DETERMINATION OF INTERLIM ANGLE

1900 REM

1910 REM FOR THE SAKE OF DETERMINING INTERLIMB ANGLE, DATA OF THE TWO LIMBS MUST BE ROTATED TO VERTICAL PLANE

1920 FOR I $=1$ TO 2

1930 IF DR $<90$ THEN REV=90- DR : ADDR(I) = ADDR(I) + REV

1940 IF DR $>90$ THEN REV $=$ DR $-90: \operatorname{ADDR}(\mathrm{I})=\operatorname{ADDR}(\mathrm{I})-\mathrm{REV}$

1950 ADPL(I) $=$ ADPL(I) *3.142857 / 180

$1960 \operatorname{ADDR}(\mathrm{I})+\operatorname{ADDR}(\mathrm{I}) * 3.142857 / 180$

$1970 \mathrm{R}=\mathrm{DP} * 3.142857 / 180$

1980 REM CALCULATING THE PARAMETERS L, M AND N BEFOR ROTATION

$1990 \mathrm{~L} 1=\operatorname{COS}(\operatorname{ADPL}(\mathrm{I})) * \operatorname{SIN}(\operatorname{ADDR}(\mathrm{I}))$

$2000 \mathrm{M} 1=\operatorname{COS}(\operatorname{ADPL}(\mathrm{I}) * \cos (\operatorname{ADDR}(\mathrm{I}))$

$2010 \mathrm{~N} 1=\mathrm{SIN}(\mathrm{ADPL}(\mathrm{I})$

2020 REM CALCULATING L, M AND N PARAMETERS AFTER ROTATION

$2030 \mathrm{~L} 2=\mathrm{L} 1 * \operatorname{COS}(\mathrm{R})+\mathrm{N} 1 * \mathrm{SIN}(\mathrm{R})$

$2040 \mathrm{M} 2=\mathrm{M} 1$

$2050 \mathrm{~N} 2=\mathrm{L} 1 *(-1) * \mathrm{SIN}(\mathrm{R})+\mathrm{N} 1 * \mathrm{COS}(\mathrm{R})$

$2060 \operatorname{ADPL} 1(\mathrm{I})=\operatorname{ATN}\left(\mathrm{N} 2 /(1-\mathrm{N} 2 \wedge 2)^{\wedge}(1 / 2)\right)$

2070 ADPL1(I) $=$ ADPL1(I) * $180 / 3.142857$

2080 NEXT I

2090 INTERLIMB $=180-($ ADPL1 $(1)+$ ADPL1 12$))$

2100 PRINT “********THE INTERLIMB ANGLE OF THIS FOLD IS = “; INT(INTERLIMB) ;”DEGREE” 2110 REM FOLD SYMMETRY

2120 REM

2130 IF $\mathrm{C}(1)>\mathrm{C}(2)$ THEN 2190

2140 IF $\mathrm{A}(2)>0$ AND $\mathrm{B}(2)>0$ THEN VERG $\$=$ "NW"

2150 IF $\mathrm{A}(2)>0$ AND $\mathrm{B}(2)<0$ THEN VERG $\$=$ " $\mathrm{SW}$ "

2160 IF $\mathrm{A}(2)<0$ AND $\mathrm{B}(2)>0$ THEN VERG $\$=$ "NE"

2170 IF $\mathrm{A}(2)<0$ AND $\mathrm{B}(2)<0$ THEN VERG $\$=$ " SE"

2180 GOTO 2230

2190 IF $\mathrm{A}(1)>0$ AND B $(1)>0$ THEN VERG $\$=$ "NW"

2200 IF $\mathrm{A}(1)>0$ AND $\mathrm{B}(1)<0$ THEN VERG $\$=$ " $\mathrm{SW}$ "

2210 IF $\mathrm{A}(1)<0$ AND $\mathrm{B}(1)>0$ THEN VERG $\$=$ "NE"

2220 IF $\mathrm{A}(1)<0$ AND $\mathrm{B}(1)<0$ THEN VERG $\$=$ " SE"

2230 IF C $(1)=\mathrm{C}(2)$ THEN PRINT" $* * * * * * * *$ THE FOLD IS SYMMETRICAL" ELSE PRINT"********THE FOLD IS ASYMMETRICAL AND VERGENT TOWARD”;VERG\$

2240 REM 
A Mathematical Technique for Analyzing Folds...

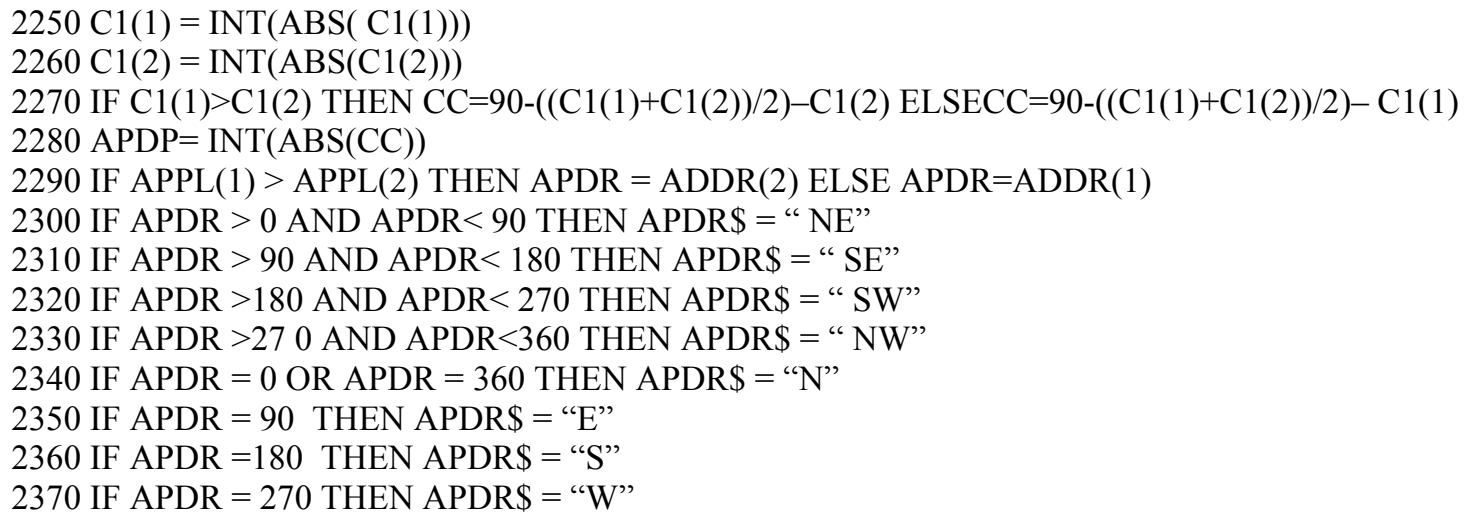


2820 IF DR3(I) $=>10$ AND DP1(I) = 90 THEN PER $=$ PER + $1:$ GOTO 2880

2830 IF DR3(I) $=>10$ AND DP1(I) $<90$ THEN 2880

2840 IF DR3(I) $<1$ THEN DR3(I) $=0$

$2850 \mathrm{XX}=\mathrm{DR} 3(\mathrm{I})$

2860 GOSUB 3240

2870 IF INT(DP1(I)) >= TLX THEN PER=PER+1

2880 NEXT I

2890 REM STANDARD CURVE FOR CYLINDRICAL FOLD.

2900 FOR $\mathrm{K}=1$ TO 10

2910 READ X(K), FX(K)

2920 DATA $0,0,10,0,20,60,30,70,40,75,50,77,60,79,70,80,80,90,80$

2930 NEXT K

2940 FOR I $=1$ TO M

2950 IF DR3(I) $=<10$ THEN SYN=SYN $+1:$ GOTO 3020

2960 IF DR3(I) $>=70$ AND DP1(I) $>=80$ THEN SYN=SYN +1 : GOTO 3020

2970 IF DR3(I) $>=70$ AND DP1(I) $<80$ THEN 3020

2980 IF DR3(I) $<1$ THEN DR3(I) $=0$

$2990 \mathrm{XX}=\mathrm{DR} 3(\mathrm{I})$

3000 GOSUB 3240

3010 IF INT(DP1(I)) >= INT(TLX) THEN SYN=SYN+1

3020 NEXT I

3030 REM STANDARD CURVE FOR SUB-CYLINDRICAL FOLD.

3040 FOR $\mathrm{K}=1$ TO 10

3050 READ X(K), FX(K)

3060 DATA $0,0,10,0,20,0,30,45,40,58,50,64,60,66,70,68,80,70,90,70$

3070 NEXT K

3080 FOR I $=1$ TO M

3090 IF DR3 (I ) $=<20$ THEN SUB=SUB +1 : GOTO 3160

3100 IF DR3 ( I ) $>=80$ AND DP1( I ) $>=70$ THEN SUB $=$ SUB $+1:$ GOTO 3160

3110 IF DR3 ( I ) $>=80$ AND DP1 ( I ) $<70$ THEN 3160

3120 IF DR3 ( I ) $<1$ THEN DR3 ( I ) $=0$

$3130 \mathrm{XX}=\mathrm{DR} 3(\mathrm{I})$

3140 GOSUB 3240

3150 IF INT (DP1 ( I )) > = INT ( TLX ) THEN SUB=SUB+1

3160 NEXT I

$3170 \mathrm{NON}=\mathrm{M}-\mathrm{SUB}$

3180 REM THE PERCENTAGE DETERMINATION OF EACH TYPE

3190 IF PER / M > = .9 THEN PRINT"******** THIS FOLD IS PERFECT CYLINDRICAL":GOTO 3230

3200 IF SYN/M>=.9 THEN PRINT"********THIS FOLD IS CYLINDRICAL":GOTO 3230

3210 IF SUB/M>. 9 THEN PRINT"********THIS FOLD IS SUB-CYLINDRICAL":GOTO 3230

3220 IF NON / M > .1 THEN PRINT" ********THIS FOLD IS NON-CYLINDRICAL “

3230 END

$3240 \mathrm{REM} * * * * * * * * * * * * * * * * * * * * * * * * * * * * * * * * * * * * * * * * * * * * * * * * * * * * * * * * * * * * * * * * * * * * * * * * * * *$

3250 REM A SUBROUTINE FOR LAGRANGIAN INTERPOLATING A POINT WITHIN A CURVE.

3260 TLX $=\mathrm{O}$

3270 FOR $\mathrm{K}=1$ TO 10

$3280 \mathrm{LU}(\mathrm{K})=1: \mathrm{LD}(\mathrm{K})=1$

3290 FOR $\mathrm{J}=1$ TO 10

3300 IF $\mathrm{K}=\mathrm{J}$ THEN 3330

$3310 \mathrm{LU}(\mathrm{K})=\mathrm{LU}(\mathrm{K}) *(\mathrm{XX}-\mathrm{X}(\mathrm{J}))$

$3320 \mathrm{LD}(\mathrm{K})=\mathrm{LD}(\mathrm{K}) *(\mathrm{X}(\mathrm{K})-\mathrm{X}(\mathrm{J}))$

3330 NEXT J

$3340 \mathrm{LX}(\mathrm{K})=\mathrm{LU}(\mathrm{K}) / \mathrm{LD}(\mathrm{K}) * \mathrm{FX}(\mathrm{K})$

$3350 \mathrm{TLX}=\mathrm{TLX}+\mathrm{LX}(\mathrm{K})$

3360 NEXT $K$

3370 RETURN

3380 REM * 